dol https://periodicos.ufpa.br/index.php/revistam

\title{
REFLEXÕES SOBRE PESSOAS SURDAS: PROBLEMATIZANDO A DIFERENÇA
}

\section{REFLECTIONS ON DEAF PEOPLE: PROBLEMATIZING DIFFERENCE}

\author{
Elenilce Reis Farias PEIXOTO ${ }^{1}$ \\ Universidade Federal do Pará
}

Marília do Socorro Oliveira ARAÚJO²

Universidade Federal do Pará

\author{
Rosângela do Socorro Nogueira de SOUSA ${ }^{3}$
}

Universidade Federal do Pará

\begin{abstract}
Resumo: Diante do contexto de inclusão nas universidades, as pessoas surdas trazem consigo uma língua distinta da que é compartilhada amplamente na academia por um grupo majoritariamente ouvinte. Pensar sobre essa questão linguística também implica nos modos de como olhar o outro. Assim, este trabalho possui como principal objetivo refletir sobre a língua de sinais como artefato cultural que demarca a diferença das pessoas surdas como sujeitos socioantropológicos. Para este trabalho, a base metodológica está ancorada em uma pesquisa exploratória, a partir da revisão bibliográfica. Os principais subsídios teóricos são Silva (2000), Bhabha (1991), Woodward (2000), Skliar (2003; 2013), Lacerda (2000; 2014), dentre outros. Os resultados apontam que é imprescindivel conceber o surdo a partir de sua diferença linguística, suas identidades são construídas e marcadas por meio da diferença. A Libras, os surdos e suas experiências visuais determinam $o$ conjunto de diferenças em relação a qualquer outro grupo de sujeitos.
\end{abstract}

Palavras-chave: Surdo. Universidade. Diferença linguística. Alteridade.

\begin{abstract}
Faced with the context of inclusion in universities, deaf people bring with them a different language from which it is widely shared in the academy by a group that is mainly listening. Thinking about this linguistic issue also implies ways of looking at the other. Thus, this work has as main objective to reflect on the sign language as a cultural artifact that marks the difference of deaf people as socioanthropological subjects. For this work, the methodological basis is anchored in an exploratory research, based on the literature review. The main theoretical subsidies are Silva (2000), Bhabha (1991), Woodward (2000), Skliar (2003; 2013), Lacerda (2000; 2014), among others. The results show that it is essential to conceive the deaf from their linguistic difference, their identities are constructed and marked through difference. Libras, the deaf and their visual experiences, determine the set of differences in relation to any other group of subjects.
\end{abstract}

Keywords: Deaf. University. Linguistic difference. Alterity.

\footnotetext{
${ }^{1}$ Universidade Federal do Pará (UFPA). Campus universitário de Abaetetuba. E-mail: nilcefariasreis@gmail.com.

${ }^{2}$ Universidade Federal do Pará (UFPA). Campus universitário de Abaetetuba.E-mail: lilia_olive@hotmail.com.

${ }^{3}$ Universidade Federal do Pará (UFPA). Campus universitário de Abaetetuba. E-mail: ronogueiraufpa@gmail.com.
} 


\section{Introdução}

Atualmente a inserção das pessoas surdas no ensino superior é uma realidade, e isso se deve às efetivações de políticas de ações afirmativas nas universidades, as quais foram e são resultados de lutas dos grupos sociais historicamente estigmatizados. Diante desse contexto de inclusão, as pessoas surdas, ao adentrarem o espaço acadêmico, trazem consigo uma língua (de modalidade visuoespacial) distinta da que é compartilhada no ambiente acadêmico por um grupo majoritariamente ouvinte, que faz o uso da língua em sua modalidade oral-auditiva.

Pensar sobre essa questão da inclusão de surdos no ensino superior implica olhar o mundo a partir do olhar do outro, a inclusão na universidade se faz pela interação, pelo contato com o outro. Assim, este trabalho possui como principal objetivo compreender a língua de sinais como artefato cultural que demarca a diferença das pessoas surdas como sujeitos socioantropológicos. O trabalho em questão faz parte de uma pesquisa em andamento que possui como objeto de pesquisa os discursos docentes sobre a inclusão de pessoas surdas no ensino superior. Dessa forma, abordaremos especificamente, nesse recorte, a parte ontológica, a questão de sujeitos surdos concebidos a partir do conceito da diferença. Nesse sentido, o estudo mobiliza os conceitos da diferença, identidade e alteridade, bem como a problematização do conceito normalidade $\mathrm{x}$ anormalidade, a fim de compreender as nuances que perpassam a questão da inclusão de pessoas surdas na universidade.

Para a construção deste trabalho, a base metodológica está ancorada em uma pesquisa exploratória, a partir da revisão bibliográfica, a qual constitui um importante subsídio ao marco teórico da pesquisa em andamento. Os principais subsídios teóricos aqui abordados são Silva (2000), Bhabha (1991), Woodward (2000), Skliar (2003; 2013), Lacerda (2000; 2014), dentre outros.

É importante situar e compreender a surdez dentro dos Estudos Surdos em Educação, que trata esse conceito pelo viés epistemológico. Assim, a surdez "constitui uma diferença a ser politicamente reconhecida; é uma experiência visual; é uma identidade múltipla ou multifacetada" (SKLIAR, 2013, p. 11). E, nesse caminho, a língua de sinais, as identidades das pessoas surdas, as experiências visuais determinam o conjunto de diferenças dos surdos em relação a qualquer outro grupo de sujeitos.

O artigo está organizado em 4 tópicos. O primeiro trata das políticas de ações afirmativas que garantem o acesso das pessoas com deficiências nas universidades. No segundo tópico deste artigo são feitas algumas asserções a respeito dos termos normal e anormal. O terceiro tópico aborda a questão das identidades das pessoas surdas e abre caminho para o último tópico, que faz conjecturas a respeito do conceito da diferença, da surdez como diferença. 


\title{
2 As políticas de ações afirmativas para pessoas com deficiência
}

A educação inclusiva ganhou força por meio das políticas públicas educacionais a favor dos direitos educacionais e sociais de pessoas com deficiência (PcD). Assim, esses alunos passaram a ter direitos que lhes garantissem não serem mais segregados dos espaços educacionais. No contexto da universidade, a própria Política Nacional de Educação Especial na Perspectiva da Educação Inclusiva estabelece que:

\begin{abstract}
$\mathrm{Na}$ educação superior, a educação especial se efetiva por meio de ações que promovam o acesso, a permanência e a participação dos alunos. Estas ações envolvem o planejamento e a organização de recursos e serviços para a promoção da acessibilidade arquitetônica, nas comunicações, nos sistemas de informação, nos materiais didáticos e pedagógicos, que devem ser disponibilizados nos processos seletivos e no desenvolvimento de todas as atividades que envolvam ensino, pesquisa e extensão (BRASIL, 2008).
\end{abstract}

Quando falamos em acessibilidade sob o ponto de vista legal, não faltam leis, decretos e portarias que falem a respeito dos requisitos de acessibilidade. É evidente ao longo dos anos o aumento de pessoas com deficiência ingressas na educação superior, essa realidade é fruto das políticas de ações afirmativas nas universidades a fim de contemplarem esse grupo social. Essas políticas de ações afirmativas são mecanismos importantes para o enfrentamento de desigualdades sociais que historicamente foram construídas. Nesse contexto, existem as políticas inclusivas nas universidades. Dentre os aparatos legais que regulamentam o acesso e permanência das pessoas com deficiência no ensino superior, está a portaria federal $n^{0} 3.284$ de 7/11/2003, do Ministério da Educação, a qual determinou, para fins de credenciamento de instituições, autorização e reconhecimento de cursos, requisitos básicos de acessibilidade.

Em vista disso, as universidades federais vieram implementando nos últimos anos políticas de ações afirmativas para diversos grupos sociais. No Pará, a Universidade Federal do Pará - UFPA veio criando um conjunto de políticas, que demarcam o novo posicionamento adotado pela instituição, o da inclusão social. Dentre essas políticas, está o programa de vagas reservadas para pessoas com deficiência em todos os cursos de graduação da UFPA. Isso se deu através da resolução $n^{\circ} 3.883$ de 21/6/2009, a qual aprova a reserva de vagas nos cursos de graduação da UFPA às pessoas com deficiência. "Art. $1^{\circ}$ Fica aprovada a reserva de uma vaga, por acréscimo, nos cursos de graduação da UFPA, aos portadores de deficiência, a partir do ano de 2011.” (UFPA, 2009).

A partir de então, o acesso ao ensino superior por pessoas com deficiência, e nesse caso, por pessoas surdas, na UFPA, deu-se por meio da implementação de cotas (conhecida como cotas PcD) 
para o ingresso ao ensino superior. Esse ingresso se dá através do Processo Seletivo (PS) da instituição, no qual é ofertada uma vaga em cada curso, distribuídas nos diversos Campi, destinadas às pessoas com deficiência. Portanto, as pessoas surdas acessam a universidade a partir da política de inclusão.

\subsection{As pessoas surdas e o acesso à universidade}

A educação inclusiva implica oferecer um espaço que seja um ambiente que acolha as minorias sociais, independente de cor, classe, gênero, etnia ou limitações individuais, que deva atender ao princípio de aceitação das diferenças conforme orientações da Política Nacional de Educação Especial na Perspectiva da Educação Inclusiva (BRASIL, 2008).

A inclusão de pessoas surdas no ensino superior é hoje uma realidade, e isso se deve ao estabelecimento de políticas de inclusão no ensino superior, porém não podemos esquecer que grande parte desses alunos traz consigo uma língua diferente da que é compartilhada no ambiente acadêmico por um grupo majoritariamente ouvinte. A língua brasileira de sinais (Libras) é uma língua viva e autônoma, possui uma gramática própria, diferente da gramática da língua portuguesa. Destarte, o aluno surdo terá um grande desafio pela frente.

$\mathrm{Na}$ perspectiva de uma educação que inclua, é fundamental a busca de medidas para a promoção do acesso aos que procuram uma igualdade educacional e social. Neste sentido, Rodrigues (2004), em sua fala sobre as instituições de ensino superior, assinala que o:

[...] acesso ao Ensino Superior está cada vez mais possível para mais jovens, o fato da formação universitária ser cada vez mais essencial para se obter uma formação profissional e emprego e, ainda, o fato das instituições de ensino superior integrarem o ensino público implicam que atualmente se equacione o caráter inclusivo da universidade, sobretudo para jovens com condições de deficiência.

A inclusão na Educação Superior é uma possibilidade que se abre para o aprimoramento da educação ocasionando ganhos sociais para toda a comunidade acadêmica. Entretanto, é preciso que a instituição esteja aberta aos desafios para lidar com as especificidades dos sujeitos da inclusão.

O contexto universitário é desafiador para todos os jovens. Problemas de adaptação à vida acadêmica e às obrigações que ela impõe conduzem muitas vezes ao fracasso e ao abandono. Para conseguir assimilar as novas informações e os novos conhecimentos, eles precisam contornar as falhas da trajetória escolar anterior, como deficiências de linguagem, inadequação das condições de estudo, falta de habilidades 
lógicas, problemas de compreensão em leitura e dificuldade de produção de textos (SAMPAIO; SANTOS, 2002).

Todas essas possíveis dificuldades devem ser consideradas para entender os desafios que os jovens surdos enfrentam para se adaptar às exigências do mundo acadêmico. A pessoa surda, ao ser considerada em sua condição linguística, pode se desenvolver e apropriar-se de novos conhecimentos de maneira adequada e satisfatória, mas, para que isso ocorra, é preciso que sejam geradas condições adequadas ao aprendizado, respeitando e propiciando o desenvolvimento e uso da linguagem (LACERDA, 2000).

Isso implica olhar o mundo a partir do olhar do outro. Desse modo, a inclusão na universidade se faz pela interação, pelo contato com o outro, ela se constrói. A inclusão de surdos (e outros grupos sociais) na universidade:

[...] envolve uma mudança de atitude face ao Outro: que não é mais um, um indivíduo qualquer, com o qual topamos simplesmente na nossa existência e com o qual convivemos certo tempo, maior ou menor, de nossas vidas. O Outro é alguém que é essencial para nossa constituição como pessoa e dessa Alteridade é que subsistimos, e é dela que emana a Justiça, a garantia da vida compartilhada (MANTOAN, 2004, p. 81).

Dito isso, não se cria mecanismos de participação social para pessoas com deficiência quando não se tem interação, quando não se coloca no lugar do outro. Uma instituição para ser inclusiva precisa ser uma instituição das diferenças, do lugar de pertencimento dos sujeitos, um espaço de convívio de culturas, com diferentes formas de ser e estar no mundo.

\section{3 É preciso superar a lógica binária}

A lógica binária é uma forma de distribuição desigual do poder entre dois termos de uma oposição (SKLIAR, 2003). Criou-se a categoria normalidade para melhor controlar o que está fora dela. Dessa forma se funda uma identidade pela oposição normal x anormal, ouvinte x surdo, saúde x patologia, produto de uma ciência interessada na correção do desvio, na reabilitação do deficiente. Essa questão das oposições binárias:

[...] constitui, na atualidade, um dos fatores mais nocivos à análise da realidade educacional, e seu enraizamento ideológico parece não apenas inevitável como também insuperável [...] Tais oposições sugerem sempre o privilégio do primeiro termo, normalidade, ouvinte, maioria, oralidade etc. em uma metanarrativa que define o significado da norma cultural. $\mathrm{O}$ termo secundário, nessa dependência 
hierárquica, ou seja, anormalidade, minoria, surdo etc., não existe fora do primeiro, mas dentro dele (SKLIAR, 2013, p. 20).

Na relação entre um e seu outro, o outro da oposição binária, existindo então fora do primeiro termo, tem sua imagem velada, sua expressão negativa, como sendo necessitada de correção normalizadora. A surdez como anormalidade incorpora uma ideologia que sustenta relações de dominação, sustenta o discurso hegemônico do ouvintismo (que limita o direito do surdo de acessar seu sistema linguístico nos diversos espaços, na vida social).

A surdez como anormalidade constitui sinônimo de falta orgânica, e sobre o surdo teceramse narrativas inscritas na ordem do discurso sobre as deficiências, traduzindo-os em identidades deficientes, objetos de desejo de reparo, sempre em via de reabilitação, para conformá-los à normalidade ouvinte-falante. Essa produção se deu através de técnicas de disciplinamento das anormalidades orgânicas dentro das clínicas médicas e em espaços escolares. Foucault (2001) ressalta como esses discursos atuavam em busca da ordem, pois, se antes eram engendrados para a reclusão ou o extermínio, agora são destinados à normalização. Todas as técnicas de disciplinamento foram desenvolvidas para que os sujeitos chegassem o mais próximo do normal e se comportassem como tal. "Por isso, a anormalidade é o outro da norma, o desvio é o outro da lei a cumprir, a doença é o outro da saúde [...], e esta dependência não é simétrica" (SKLIAR, 2003, p, 115).

O ouvintismo, como um conjunto de práticas e discursos normalizadores, expressa e inculca formas de dominação e controle, faz-se presente, não raro, de formas naturalizadas e pouco visíveis.

A normalização é um dos processos mais sutis pelos quais o poder se manifesta no campo da identidade e da diferença. Normalizar significa eleger - arbitrariamente uma identidade específica como o parâmetro em relação ao qual as outras identidades são avaliadas e hierarquizadas. Normalizar significa atribuir a essa identidade todas as características positivas possíveis, em relação às quais as outras identidades só podem ser avaliadas de forma negativa. A identidade normal é "natural", desejável, única. A força da identidade normal é tal que ela nem sequer é vista como uma identidade, mas simplesmente como a identidade (SILVA, 2000, p. $83)$.

Nessa perspectiva, esse binarismo normal/anormal leva à compreensão de que o surdo é sempre "menos" que o ouvinte, está sempre na desvantagem, sempre no esforço de adaptar-se às condições dos ouvintes. Paira sobre o surdo um estigma de deficiente, o qual supostamente teria que lutar para ser igual ao ouvinte, que seria o modelo ideal.

Segundo Skliar (2013), a forma mais presente do poder (no contexto da surdez, do ponto de vista epistemológico) se dá através do ouvintismo como ideologia dominante. As representações dos 
ouvintes sobre a surdez, de forma geral, refletem um posicionamento histórico que a enquadra no campo da doença, deficiência, do que destoa da normalidade. No caso dos surdos ouvintizados, estes passam a aceitar a estereotipia forjada para eles no senso comum. Essa ótica pode tornar-se, assim, avassaladora e destituidora de identidades.

Quando as pessoas surdas são identificadas como anormais, deficientes, incapazes, essa identificação destoa da perspectiva da diferença, na qual a surdez é marcada pela diferença, a diferença linguística e não pela deficiência.

\section{Identidades das pessoas surdas}

As mudanças e transformações globais nas estruturas políticas e econômicas no mundo contemporâneo colocam em evidência a questão das identidades e as lutas pela afirmação e manutenção das identidades nacionais e étnicas. É importante reconhecer que a luta e contestação se fundam na construção cultural de identidades como um fenômeno que circula em diferentes contextos (SILVA, 2000). Nesse sentido, no contexto da surdez, marcada como diferença, há a contestação de afirmação das identidades das pessoas surdas, produzindo assim novas formas de posicionamento.

Assim, a língua de sinais constitui-se como instrumento de afirmação linguística e identitária das pessoas surdas. Perlin (2003, p. 57) nos oferece uma significativa contribuição quando afirma que: "O surdo na experiência de ser surdo se sente o outro, e as resistências, devido à imposição da experiência ouvinte, quando não são acompanhadas de silêncio, são resistências povoadas de significados", resistências essas que contestam e reafirmam as identidades.

O conceito de identidades encontra caminho nos pressupostos teóricos dos Estudos Culturais, que é um campo atuante nos Estudos Surdos. Wrigley (1996) atenta para a importância de pensar a surdez no nível epistemológico, o qual vai além do viés conceitual de patologia. Ao trabalharem com o conceito de identidade, os Estudos Culturais tomam como pensamento o de que a existência da identidade de um somente existe em relação ao outro, o diferente. Por isso, a identidade e a diferença estão intimamente entrelaçadas, uma não convive sem a outra. A identidade surda se constrói dentro de uma cultura visual e essa diferença precisa ser entendida não como uma construção isolada, e sim como construção multicultural e histórica.

Para Perlin (2003, p. 52), “a identidade é algo em questão, em construção, uma construção móvel que pode frequentemente ser transformada ou estar em movimento, e que empurra o sujeito em diferentes posições". Em outras palavras, a "identidade surda" diz respeito principalmente ao processo de reconhecimento e de identificação do surdo com os seus iguais; ao uso da língua de sinais 
e, para alguns, ao direito de querer ser surdo. Pode ser percebida, ainda, em algumas de suas facetas, através de práticas sociais específicas, como a resistência frente à presença hegemônica ouvinte ou o percurso de lutas do movimento surdo. Destarte, a construção das identidades surdas irá depender da relação que esses sujeitos mantêm com o discurso de fundamentação ouvintista, por um lado, e com o discurso de fundamentação surda, por outro. As identidades surdas (identidades surdas, transitória, incompleta, híbrida e flutuante ${ }^{4}$ ) são dispersas, não fixas e temporárias, e constituem um sujeito surdo multifacetado.

A partir da compreensão de que as pessoas surdas são sujeitos multiculturais, multifacetados, que constroem suas identidades a partir da diferença e na relação com o outro, foram se construindo frentes de lutas na busca por direitos linguísticos, de acessibilidade e de inclusão social.

\section{Surdez como diferença}

Identidade e diferença são conceitos que estão em uma relação de estreita dependência. $\mathrm{Na}$ linha dos Estudos Culturais (HALL, 2006; SILVA, 2000), identidade e diferença são atos de criação linguística, produzidos ativamente no discurso. A afirmação da identidade e da diferença no discurso traduz conflitos de poder entre grupos assimetricamente situados. A identidade e a diferença são conceitos importantes em teorias críticas, interessadas na investigação de relações de dominação (FAIRCLOUGH, 2003).

Nessa perspectiva, a identidade é "marcada pela diferença" (WOODWARD, 2000, p. 15). É construída a partir da diferença, da percepção de si e do outro e da valorização do eu. Localizar a surdez dentro dos Estudos Surdos em Educação é compreender que a surdez "constitui uma diferença a ser politicamente reconhecida; é uma experiência visual; é uma identidade múltipla ou multifacetada" (SKLIAR, 2013, p. 11). Nesse sentido, esse campo de estudo vem justamente problematizar aquilo que não é problematizado, pontuar que o problema não é a surdez, não são os surdos e surdas, tampouco a língua de sinais, mas sim as representações dominantes, hegemônicas e ouvintistas sobre os tais. Outrossim, falar da diferença provoca uma problematização sobre normalidade e anormalidade e inclusive a problematização da própria normalidade.

Outro aspecto importante a ser colocado aqui é a distinção entre diversidade e diferença. $\mathrm{O}$ discurso da diversidade tenta esconder, negar as diferenças, pois a diversidade cria um falso consenso, uma ideia de que a normalidade hospeda os diversos, colocando-os todos no mesmo patamar de

\footnotetext{
${ }^{4}$ Para maior aprofundamento sobre as múltiplas identidades surdas, ver Perlin (2003).
} 
igualdade. Todavia, "o universalismo que permite paradoxalmente a diversidade mascara normas etnocêntricas" (BHABHA, 1991, p. 208) e serve para abafar a diferença, entra aqui um esforço de universalizar o surdo através de mecanismos de integração, onde se admite o diverso, porém não a diferença. Isso nos faz refletir: se não houvesse diferenças, logo não haveria motivos para metodologias diferenciadas para pessoas surdas, porque todos supostamente aprenderiam do mesmo jeito. Entretanto, essa é uma premissa equivocada, pois educar significa introduzir uma cunha da diferença em um mundo que sem ela se limitaria a reproduzir o mesmo e o idêntico, é acolher o outro em sua irredutível diferença.

Respeitar a diferença não pode significar "deixar que o outro seja como eu sou" ou "deixar que o outro seja diferente de mim tal como eu sou diferente (do outro)", mas deixar que o outro seja como eu não sou, deixar que ele seja esse outro que não pode ser eu, que eu não posso ser, que não pode ser um (outro) eu; significa deixar que o outro seja diferente, deixar ser uma diferença que não seja, em absoluto, diferença entre duas identidades, mas diferença $d a$ identidade, deixar ser uma outridade que não é outra "relativamente a mim" ou "relativamente ao mesmo", mas que é absolutamente diferente, sem relação alguma com a identidade ou com a mesmidade (PARDO, 1996, p. 154 apud SILVA, 2000, p. 101).

Dito isto, cabe refletir sobre a diferença do múltiplo e não do diverso, a multiplicidade estimula a diferença, a qual se recusa conjugar-se com o idêntico. Nesse caminho da diferença do outro, surdez é descrita em termos contrários às noções de deficiência e patologia, vem a partir de uma concepção social e antropológica, na qual adentra o campo da diferença, da surdez como diferença política. Skliar (2013, p. 06) compreende a diferença como significação política que é:

[...] construída histórica e socialmente; é um processo e um produto de conflitos e movimentos sociais, de resistências às assimetrias de poder e de saber, de outra interpretação sobre alteridade e sobre o significado dos outros no discurso dominante.

Nessa perspectiva, as identidades são construídas por meio da diferença e não fora dela (SILVA, 2000). Isso implica então no reconhecimento de que é apenas por meio da relação com o outro que o significado positivo de qualquer termo pode ser construído. A identidade, portanto, é marcada pela diferença.

\section{Conclusão}

Chegamos aqui entendendo que é imprescindível conceber a diferença do outro, a surdez é descrita em termos contrários às noções de deficiência e patologia, ela vem a partir de uma concepção 
social e antropológica. Nesse caminho, a língua de sinais, as identidades das pessoas surdas, as experiências visuais determinam o conjunto de diferenças dos surdos em relação a qualquer outro grupo de sujeitos. Assim, as identidades são construídas por meio da diferença e não fora dela, sendo, dessa forma, marcadas pelas diferenças.

Portanto, uma educação voltada para pessoas surdas precisa considerar a língua de sinais como artefato cultural (objetos, tradições, valores, normas) do povo surdo, sua experiência visual e linguística, pois são importantes para disseminação de sua cultura e afirmação da identidade. Assim, a língua de sinais constitui-se como a diferença linguística das pessoas surdas a ser reconhecida em todos os espaços sociais, a saber, a universidade.

\section{Referências}

BHABHA, Homi K. A questão do outro: diferença, discriminação e o discurso do colonialismo. In: HOLANDA, H. B. de (org.). Pós-modernismo e cultura. Rio de Janeiro: Rocco, 1991. (Tradução de: The location of culture).

BRASIL. Política Nacional de Educação Especial na Perspectiva da Educação Inclusiva. Brasilia: Ministério da Educação, 2008.

FAIRCLOUGH, Norman. Analysing discourse: textual analysis for social research. Londres: Routledge, 2003.

FOUCAULT, Michel. Os Anormais. São Paulo: Martins Fontes, 2001.

HALL, Stuart. A identidade cultural na pós-modernidade. Rio de Janeiro: DP\&A, 2006.

LACERDA, Cristina Broglia Feitosa de. A prática pedagógica mediada (também) pela língua de sinais: trabalhando com sujeitos surdos. Caderno Cedes. Campinas, v.20, n. 50, abr. 2000.

LACERDA, Cristina Broglia Feitosa de; SANTOS, Lara Ferreira dos. Tenho um aluno surdo, e agora? Introdução à Libras e educação de surdos. São Paulo: EDUFSCAR, 2014.

PERLIN, Gladis Terezinha Taschetto. O Ser e o estar sendo surdos: Alteridade, Diferença e Identidade. 2003. Tese (Doutorado em Educação) - Universidade Federal do Rio Grande do Sul. Porto Alegre, 2003. 
RODRIGUES, David. A inclusão na universidade: limites e possibilidade da construção de uma universidade inclusiva. Cadernos de Educação Especial, Santa Maria, n. 23, 2004.

SAMPAIO, Isabel S.; SANTOS, Acácia A. Leitura e redação entre universitários: avaliação de um programa de intervenção. Psicologia em Estudo, Maringá, v.7, n.1, p.31-38, jan. 2002.

SILVA, Tomas Tadeu da. (org.). Identidade e diferença: a perspectiva dos estudos culturais. $6^{\mathrm{a}}$ ed. Petrópolis: Vozes, 2000.

SKLIAR, Carlos. Pedagogia (improvável) da diferença: e se o outro não estivesse aí? Trad. Giane Lessa. Rio de janeiro: DP\&A, 2003.

SKLIAR, Carlos (org.). A surdez: um olhar sobre as diferenças. $6^{\mathrm{a}}$ ed. Porto Alegre: Mediação, 2013.

WRIGLEY, Owen. A política da surdez. Washington: Gallaudet University, 1996.

WOODWARD, Kathryn. Identidade e diferença: uma introdução teórica e conceitual. In: SILVA, Tomaz Tadeu (org.). Identidade e diferença. A perspectiva dos estudos culturais. Rio de Janeiro: Vozes, 2000, p. 7-39. 